\title{
Kawaii Culture in Japan: A Bibliometric Analysis and Text Mining Approach Based on Pop-Cultural Diplomacy and Transmission into Global Values
}

\author{
Hiroko Oe ${ }^{1}$, Max Weeks ${ }^{2}$ \\ ${ }^{1}$ The Business School, Bournemouth University, UK \\ ${ }^{2}$ Brockenhurst college, UK \\ hoe@bournemouth.ac.uk
}

\begin{abstract}
This research aims to develop a discussion framework for Kawaii cultural study based on a bibliometric analysis and text mining approach. First, a bibliometric analysis is conducted on literature pertaining to 'Kawaii and Japanese pop culture' extracted from the academic database; from this standpoint, the current research topics in the field of Kawaii study are discussed. Second, we aim to provide direction for future research by mining the text data disseminated by three special exhibitions launched by Japanese museums on the theme of 'Japanese Kawaii culture' and planned by Kawaii cultural experts and curators. From the results of these two studies, the present research develops a discussion framework containing key dimensions and factors for researchers in this field of study.
\end{abstract}

\section{Keywords}

Kawaii; Japan; pop-culture diplomacy, inbound tourism global value; bibliometric analysis, VOS viewer, thematic analysis, text mining, $\mathrm{KH}$ Coder

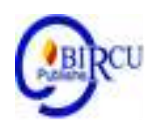

\section{Introduction}

\subsection{Background of this Study}

Since the 20th century, Japanese Kawaii culture has been admired and studied all over the world. Research results in English on this topic have accumulated to a certain extent, and the question of how 'Kawaiiness' - as contemporary Japanese pop culture originating in Japan - has been accepted and consumed by other countries has been attracting interdisciplinary researchers around the world. In particular, at present, Kawaiiness' new social and cultural value in the context of globalisation has been a key topic of interest among cultural researchers.

On the other hand, in Japan, the birthplace of Kawaii culture, some more historic and holistic discussion is common: for instance, Yumeji Takehisa in the Taisho era (19121926) has been posited as the movement's originator, and since that time, Osamu Harada, who was most popular in the Showa era (1926-1989) has gained a certain core fanbase. Harada is also thought to be an artist who cultivated a younger generation of fans among teenagers and high school students.

\subsection{Rationale of the Study}

As has been noted Kawaii and Japanese contemporary pop culture is a popular research topic in English-speaking academia (see e.g. Koma, 2013; Nittono, 2016; Hiramoto and Wee, 2019). It has been one of the popular themes for researchers to discuss the process of cultural transmission to the global context through Japanese pop culture media such as anime and manga; whereas the views of Japanese Kawaiiness experts are not necessarily studied and recognised by Kawaii researchers in the rest of the world (Pellitteri, 2018). At the same time, given that Japan is the origin of Kawaii culture, a discussion framework developed from Japanese sources would further enhance discussions 
in global cultural studies academia. Therefore, this study aims to review relevant academic sources and to provide a discussion agenda containing key dimensions and factors for researchers in this field of study.

\section{Review of Literatures}

\subsection{Kawaii in Pop Culture}

The word Kawaii has become well-known almost everywhere in the world. Celebrities such as Stephanie Nguyen, Madonna, Lady Gaga, Ariana Grande, and others have found the Japanese Kawaii goods attractive, and praising Japanese Kawaiiness: it is now certainly a word that represents Japanese pop culture (Van Haecke, 2020). The word is defined in the Oxford English Dictionary as 'cute in the context of Japanese popular culture' (Ohkura, 2019).

In recent years, Kawaii culture has expanded to include Yuru-chara (mascots), Hello Kitty and other Sanrio characters, various anime, fancy colourful pop stationaries and even music (Kerr, 2016). Many artists have also begun to pay attention to Kawaii culture of late, and various anime characters and collaborative works have been produced. Takashi Murakami even recently released a work themed around the character Doraemon.

Cho (2017) also discussed the impact of Japanese Kawaii culture in the broader context of eastern Asia, while Sabre (2018) emphasised the impact of Kawaiiness on increasing the number of inbound tourists to certain destinations. On this point, the Japanese government has been embracing Kawaii culture as one of the key appealing elements of tourism in Japan, launching an inbound tourism project with a focus on Tokyo 2020 by creating various media messages under campaigns of 'Pop-Culture Diplomacy' (Ministry of Foreign Affairs, 2012; 2017). Responding to the impact delivered by Japan, appreciations and reactions from overseas to Kawaiiness originating in Japan have increased, both in practice and in academia (e.g., StarLifestyle, 2015; Berque et al. 2019; Laohakangvalvit et al. 2019; Lieber-Milo and Nittono, 2019; Yamamura and Seaton 2020).

In this research, Kawaii in pop culture is discussed with reference to four subthemes: (1) contemporary analytical perspectives; (2) the role of cultural diplomacy in tourism; (3) global transmission of the Kawaii value; and (4) the future research agenda of Kawaii cultural studies, referring to the relevant academic discussions.

\subsection{Mainstream Academic Discussions}

\section{a. Kawaii in the Contemporary Cultural Studies Context}

Koma (2013) suggested that Kawaii should be a key topic in the field of cultural studies; in line with this, Nittono (2016) presented an analytical model for behavioural research into Kawaii fans. More recently, some specific contemporary topics have focused on Kawaiiness' impact on gender-related prejudice, implying that the concept is embedded in conventional gender perspectives and with a focus on the attitudes of young females towards Kawaii goods (e.g. Iseri, 2015; Xie, 2020). Lieber-Milo (2019b) conducted a cross-sectional study with Japanese women consumers to analyse their different perspectives on Kawaii. For working women, it was found that 'Kawaii products help in dealing with stress and serve as a momentary gateway from the harsh world of everyday life', while for younger women, it was noted that Kawaii 'serve[s] as a fashion statement' (Lieber-Milo (2019b:1).

Additional interdisciplinary analyses have also been conducted specifically in the engineering field of study, and there has been an accumulation of empirical and experimental research regarding what attributes of Kawaii products have a positive impact 
On consumers' psychological and emotional affect (e.g. Cheok, 2010; Nittono, 2019; Ohkura, 2019). Hiramoto (2019) also opened up a new research paradigm for Kawaii cultural studies under the scope of the semiotic and sociolinguistic approach.

\section{b. Kawaii and the Role of Cultural Diplomacy in Tourism}

As discussed above, the Japanese government has been utilising the power of Kawaii culture to conduct pop-cultural diplomacy in order to attract tourists to Japan (e.g., Iwabuchi, 2015; Clarke, 2016). Clarke (2016) discussed how cultural product consumption might be theorised based on academic cultural studies perspectives. Beeton et al. (2016) and Beeton (2019) contended that cultural studies should focus on the key theme of mediatisation, which also implies that the process could support enhancing discussions in the context of the globalisation of pop culture and its impacts on tourism.

Yamamura and Seaton (2020) focused more narrowly on the potential of pop culturebased tourism; these authors were followed by Jang (2020), who researched the impact of pop cultural destinations with Kawaiiness in the era of mobility. Sabre (2019) discussed the topic of tourism marketing of pop culture and relevant content. Overall, these scholars suggested prospective 'Kawaii pilgrimages' to attract tourists from overseas.

\section{c. Kawaii Culture's Transmission as a Global Value}

Another key approach in Kawaii research has been the analysis of the process by which Kawaii is transmitted to the global market (e.g. Pellitteri, 2018; Lieber-Milo and Nittono, 2019a).

A comparative study of the actual conditions of Kawaii's transmission to foreign countries and its acceptance in these countries has been one of the mainstream discussions in this field of study. Berque et al. (2019) provided a cross-cultural analytical framework for Kawaii's globalisation, while Lieber-Milo and Nittono (2019b) investigated how the Japanese term Kawaii has been accepted and perceived in foreign countries. A recent major work by Duman (2020) discussed the details of Japanese Kawaii culture along with a categorisation of goods for fans, which is a useful analytical framework for researchers in this field of study.

As noted by Duman (2020), another recent research topic in the Kawaii studies is the consumption of Kawaii outside of Japan in the diversified cultural context (see e.g. Goldstein-Gidoni, 2015; Laohakangvalvit et al. 2019; Sripian et al. 2019). For instance, to a certain extent, a body of research has accumulated regarding Thai consumers; for example, Toyoshima (2018) has provided an analytical framework for the East Asian markets, with actionable implications for researchers in the area.

\section{d. Future Perspectives of Kawaii Culture in the Global Context}

In addition to the large body of research discussed so far, future perspectives on Kawaii cultural studies in the global context have also been proposed. Heng (2014) discussed the necessity of and potential for cultivating new horizons for Kawaii research that focus on its normative soft power, which contributes to global issues by coordinating different cultural and societal values. Interestingly, Chen (2020) has acknowledged the hidden power of Kawaii as an 'unspoken incantation' that fosters empowerment among its fans and related businesses. Steger et al. (2020) and Tompkins et al. (2020) suggested a new research direction in the femininities based on the current evidence that the majority of Kawaii consumers are women. Before these authors proposed this direction, Hashizume and Kurosu (2019) also discussed the topic of gender's impact on the association of Kawaii with the conventional Western concept of cuteness. 


\subsection{An Analytical Approach Based on the Categorisation of Academic Discussions}

While the main aim of the present study is to analyse and discuss Kawaii culture in both Japanese and global market contexts, based on the literature review conducted in this section, secondary data will also be systematically reviewed and evaluated to develop a further research framework for Kawaii thematic analysis in the cultural studies context. Following the categorisation of key directions of Kawaii study, this research will focus on three key terms: 'Kawaii', 'pop culture', and 'globalisation'. The next section discusses the methodological approach adopted by the study.

\section{Research Methods}

\subsection{Data Collection and Analytical Approach}

A descriptive analysis is applied to the secondary data, which comprises two steps. First, bibliometric analysis is conducted on article data extracted from the Web of Science database. The collected data was then analysed with the VOS viewer software package (van Eck and Waltman, 2020). Second, text data collected from three Japanese museums' curated events on the theme of Kawaii culture in Japan were analysed using the text mining program KH Coder (Higuchi, 2020a).

\subsection{Data Sources}

For step one, relevant academic sources were searched and collected from Web of Science using three key search terms: 'Kawaii', 'pop culture', and 'globalisation'. In doing so, to incorporate all relevant terms stemming from these three keywords, \{'Kawaii' or 'kawaii'\} AND \{'pop culture' or 'pop-culture'\} AND global* were searched, so that (for example) both 'globalization' and 'globalisation' would be picked up. The sources were set to be all years with the indexes of SCI-EXPANDED, SSCI, A\&HCI, CPCI-S, CPCI$\mathrm{SSH}, \mathrm{ESCI}$ within the Web of Science database.

After the procedure described above was conducted, bibliometric analysis was conducted with the extracted data, which was entered into the VOSviewer software package. VOSviewer was developed and distributed by Leiden University for researchers, enabling them to develop co-occurrence maps of cited words and create analytical diagrams for time-spanned research topics (Ding and Yang, 2020).

After conducting bibliometric analysis, thematic analysis was conducted on the data sources collected from three special museum exhibitions in Japan from 2011-2020 on the theme of 'Japanese pop culture Kawaii'. For text mining, the KH Coder software program was used to develop a descriptive analysis of frequently used key terms, which was followed by a correspondence map with multivariate analysis and visualisation using $\mathrm{R}$ (Higuchi 2020b). The developed map presents the visualised relationship between the extracted words and external variables as a scatterplot.

After developing the correspondence map, a hierarchical clustering map was developed with the Jaccard coefficient to determine the degree of word-to-word cooccurrence and create clusters (Higuchi, 2020b). In this chart, words closely associated with each other are connected as one group, while closely associated clusters are merged with the final complete cluster of analysed text data (Baltranaite and Povilanskas, 2019).

From these two steps of analysis, an analytical agenda containing key dimensions with thematic topics can be proposed for further discussion in the field of study. 


\section{Results and Discussion}

\subsection{Study 1: Bibliometric Analysis of 'Kawaii' and 'Pop Culture'}

As demonstrated in Table 1, 44 items were extracted from 1,155 academic sources collected from Web of Science; as can be seen from the table, a total of six clusters were created.

Figure 1 to 3 present a density visualisation, an overlay visualisation, and a cooccurrence network map respectively. Table 2 lists the results of cluster development, with 44 key terms extracted for the bibliometric analysis (over the frequencies of five times). The biggest cluster, which includes 10 words, implies that Kawaii-related goods consumption is backed up by celebrities with an identified image, and also indicates that Kawaii fans have some consumption power. The second-biggest cluster, which also includes 10 words, implies that Japanese Kawaiiness is associated with Japanese anime and manga, and further indicates that Japanese Kawaii is discussed as the core value of Japanese pop culture. Moreover, cluster 3 indicates a word group of analytical scope, which is coupled with the key terms of gender, globalisation, and ideological factors. Clusters 4-6 indicate that further comparative analytical context has been another core topic for the study, referring to cinema, social media, and other domains of cultural studies such as music.

Table 1. Clusters and key words for bibliometric analysis

\begin{tabular}{|l|}
\hline Cluster 1 (10 items) \\
\hline celebrity \\
consumption \\
culture \\
fandom \\
feminism \\
identity \\
image \\
masculinity \\
politics \\
power \\
Cluster 2 (10 items) \\
anime \\
chinese \\
japan \\
japanese \\
kawaii \\
manga \\
motivation \\
pop-culture \\
popular-culture \\
soft power
\end{tabular}

Cluster 3 ( 9 items)
discourse analysis
gender
globalization
ideology
media
popular culture
religion
television
women
Cluster 4 ( 7 items)
art
cinema
cultural studies
fans
myth
performance
pop culture
Cluster 5 ( 5 items)
adolescents
behavior
evolution
perceptions
social media
Cluster 6 ( 3 items)
k-pop
music
race

Figures 1-3 also present a heuristic view of the bibliometric outcomes. Figure 1 suggests that Kawaii discussions are related to the core theme of pop culture, whereas Figure 2 demonstrates researched themes according to the timeframe; as the figure indicates, more recent research themes have shifted to an international comparative approach with other markets in the global context. Finally, Figure 3 presents a cooccurrence network map of bibliometric data for 'Kawaii' and 'pop culture' in the 'globalisational' context. 
Table 2. Cluster data of 44 items

\begin{tabular}{|c|c|c|c|c|c|c|c|c|c|c|}
\hline id & label & $x$ & $y$ & cluster & $\begin{array}{c}\text { weight }<\mathrm{Li} \\
\text { nks }>\end{array}$ & $\begin{array}{c}\text { weight }<\text { To } \\
\text { tal link } \\
\text { strength> }\end{array}$ & $\begin{array}{l}\text { weight }<0 \mathrm{c} \\
\text { currences }>\end{array}$ & $\begin{array}{l}\text { score<Ave } \\
\text { pub. year> }\end{array}$ & $\begin{array}{l}\text { score<Avg } \\
\text { citations }>\end{array}$ & $\begin{array}{c}\text { score<Avg } \\
\text { norm. } \\
\text { citations }>\end{array}$ \\
\hline 33 & adolescents & 0.7404 & 0.3768 & 5 & 7 & 10 & 5 & 2019.2 & 0.6 & 0.9506 \\
\hline 86 & anime & 0.3916 & -0.189 & 2 & 18 & 21 & 8 & 2018.5 & 1.5 & 1.9273 \\
\hline 117 & art & -0.5012 & -1.014 & 4 & 3 & 4 & 5 & 2018.4 & 0.8 & 1.0172 \\
\hline 173 & behavior & 0.8435 & 0.5561 & 5 & 6 & 7 & 5 & 2018 & 2.4 & 1.7657 \\
\hline 233 & celebrity & -0.7804 & 0.077 & 1 & 9 & 12 & 5 & 1614.2 & 4.6 & 4.8415 \\
\hline 250 & chinese & 1.0625 & -0.2101 & 2 & 11 & 14 & 7 & 2018 & 1.1429 & 1.5582 \\
\hline 262 & cinema & -0.8607 & -0.482 & 4 & 6 & 10 & 6 & 2019 & 0 & 0 \\
\hline 322 & consumption & -0.6679 & -0.2929 & 1 & 9 & 10 & 6 & 2018.333 & 1.1667 & 1.3098 \\
\hline 403 & cultural studies & -0.6761 & -0.6349 & 4 & 11 & 11 & 5 & 2017.8 & 0 & 0 \\
\hline 408 & culture & -0.3725 & -0.0636 & 1 & 9 & 11 & 12 & 2018.25 & 2.8333 & 2.2338 \\
\hline 469 & discourse analysis & 0.1526 & 0.8401 & 3 & 7 & 7 & 5 & 1614.6 & 0.4 & 0.4283 \\
\hline 547 & evolution & 0.9338 & 0.2978 & 5 & 7 & 9 & 5 & 2017 & 5.2 & 2.3022 \\
\hline 578 & fandom & -0.6747 & -0.0442 & 1 & 8 & 12 & 9 & $\begin{array}{ll}9 & 1794.222\end{array}$ & 1.8889 & 1.902 \\
\hline 581 & fans & -0.3973 & -0.586 & 4 & 9 & 14 & 5 & $5 \quad 2019$ & 1.2 & 1.4905 \\
\hline 603 & feminism & -0.9944 & 0.2691 & 1 & 10 & 13 & 7 & 1729.857 & 1.1429 & 1.3275 \\
\hline 664 & gender & -0.0395 & 0.4547 & 3 & 20 & 35 & 20 & 1917.25 & 1.05 & 0.91 \\
\hline 689 & globalization & -0.297 & 0.843 & 3 & 6 & 6 & 8 & 2018.25 & 1.5 & 1.8631 \\
\hline 779 & identity & -0.1007 & 0.0975 & 1 & 16 & 24 & 15 & $\begin{array}{ll}5 & 1883.333\end{array}$ & 3.5333 & 2.7328 \\
\hline 784 & ideology & 0.341 & 0.7963 & 3 & 7 & 8 & 5 & 2018.6 & 0.2 & 0.1477 \\
\hline 791 & image & -0.0377 & -0.5386 & 1 & 7 & 7 & 6 & $\begin{array}{ll}6 & 2018.167 \\
\end{array}$ & 2.1667 & 2.577 \\
\hline 867 & japan & 0.4584 & -0.3655 & 2 & 15 & 25 & 13 & $\begin{array}{ll}3 & 2018.231 \\
\end{array}$ & 0.9231 & 0.9515 \\
\hline 869 & japanese & 1.0259 & -0.0312 & 2 & 6 & 9 & 7 & 72018.286 & 2.5714 & 2.5919 \\
\hline 899 & $k-p \circ p$ & -0.2112 & 0.3765 & 6 & 8 & 9 & 7 & 2017.714 & 2.2857 & 2.5341 \\
\hline 903 & kawaii & 0.6715 & 0.1962 & 2 & 12 & 14 & 17 & 72018.588 & 1.5882 & 1.1075 \\
\hline 1011 & manga & 0.9633 & -0.4687 & 2 & 10 & 11 & 5 & 2018.2 & 0.4 & 0.6338 \\
\hline 1024 & masculinity & -0.8924 & 0.4385 & 1 & 6 & 6 & 6 & $\begin{array}{ll}6 & 1681.167\end{array}$ & 2 & 1.8649 \\
\hline 1034 & media & 0.0505 & 0.169 & 3 & 16 & 31 & 18 & $\begin{array}{ll}8 & 1906.333 \\
\end{array}$ & 1.6667 & 1.9523 \\
\hline 1104 & motivation & 0.7251 & -0.4854 & 2 & 13 & 16 & 5 & $\begin{array}{l}5 \\
\end{array}$ & 2.8 & 3.8381 \\
\hline 1119 & music & -0.4206 & 0.5504 & 6 & 9 & 12 & 10 & 2017.2 & 3 & 1.6489 \\
\hline 1126 & myth & -0.1541 & -0.8157 & 4 & 7 & 10 & 8 & 2018.75 & 0.25 & 0.6849 \\
\hline 1221 & perceptions & 0.6687 & -0.1125 & 5 & 7 & 8 & 5 & 2019 & 2 & 3.8875 \\
\hline 1223 & performance & -0.5028 & -0.3778 & 4 & 12 & 19 & 11 & 12018.364 & 0.7273 & 2.1256 \\
\hline 1254 & politics & -0.6611 & 0.4426 & 1 & 12 & 17 & 10 & 1817.1 & 1 & 1.2461 \\
\hline 1262 & pop culture & -0.1637 & -0.1461 & 4 & 38 & 90 & 76 & \begin{tabular}{l|l}
6 & 1991.711 \\
\end{tabular} & 1.1447 & 1.356 \\
\hline 1269 & pop-culture & 0.8784 & -0.6406 & 2 & 8 & 10 & 6 & $5 \quad 2017.833$ & 1.3333 & 1.481 \\
\hline 1272 & popular culture & -0.2607 & 0.1482 & 3 & 19 & 30 & 24 & 2018 & 0.625 & 0.517 \\
\hline 1277 & popular-culture & 0.3272 & -0.6071 & 2 & 15 & 17 & 5 & 2018.2 & 2.2 & 2.664 \\
\hline 1300 & power & -0.9565 & -0.1402 & 1 & 7 & 7 & 5 & 2018 & 1.6 & 1.7557 \\
\hline 1365 & race & -0.2514 & 0.5799 & 6 & 10 & 15 & 15 & $5 \quad 1883.533$ & 1.9333 & 1.8329 \\
\hline 1395 & religion & -0.0098 & -0.3431 & 3 & 9 & 13 & 9 & $\begin{array}{l}9 \\
2018.667\end{array}$ & 0.4444 & 0.64 \\
\hline 1526 & social media & 0.4406 & 0.5677 & 5 & 11 & 12 & 14 & $4 \quad 1873.857$ & 5.5 & 5.3151 \\
\hline 1547 & soft power & 0.6604 & -0.3053 & 2 & 11 & 14 & 7 & $\begin{array}{l}7 \quad 2018 \\
\end{array}$ & 0.7143 & 0.5495 \\
\hline 1632 & television & -0.6217 & 0.2066 & 3 & 9 & 11 & 9 & $\begin{array}{l}9 \\
9\end{array}$ & 1.5556 & 1.111 \\
\hline 1785 & women & 0.1707 & 0.6107 & 3 & 12 & 15 & 7 & 2018 & 3.4286 & 3.2574 \\
\hline
\end{tabular}




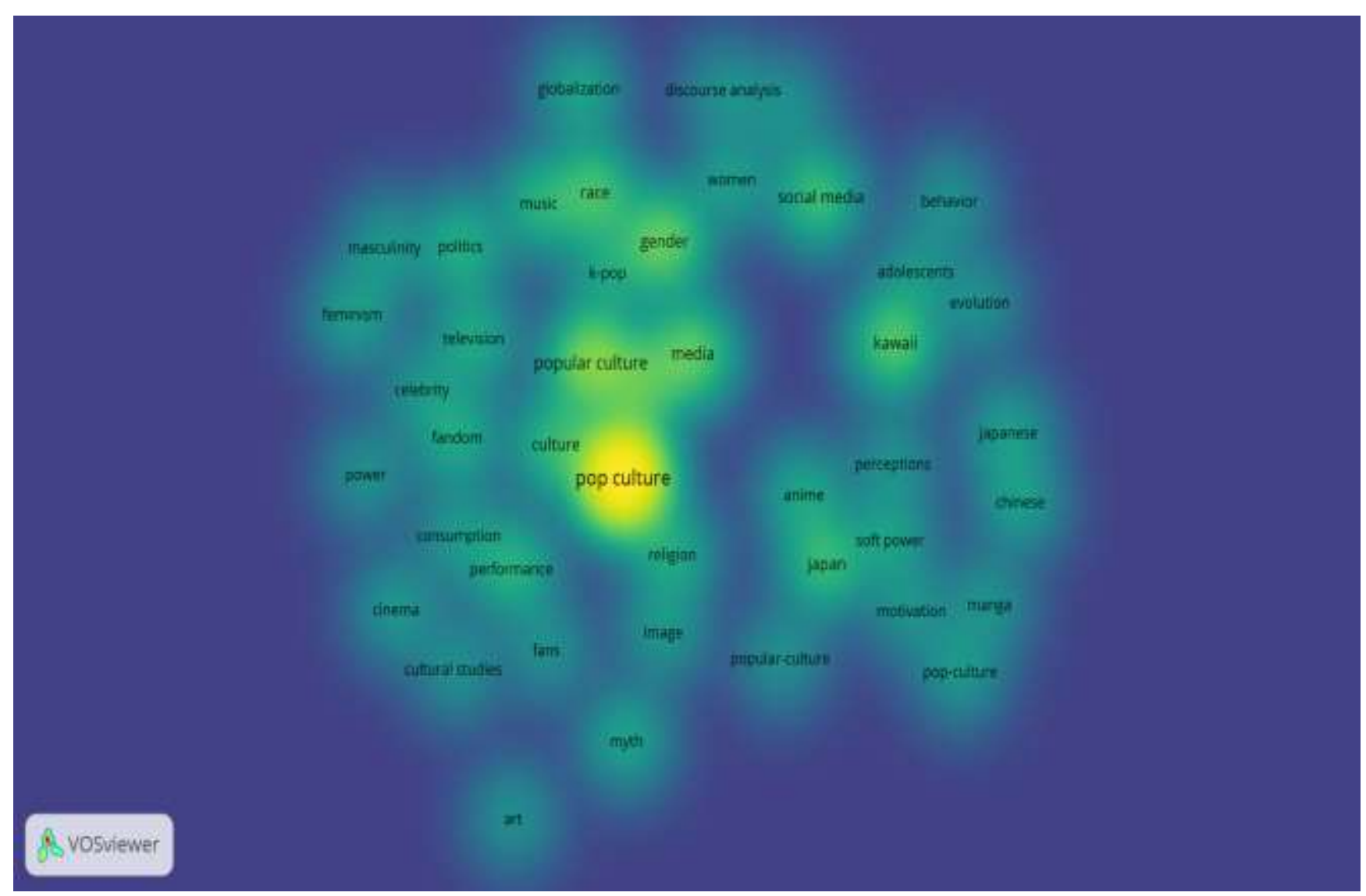

Figure 1. Density visualisation of bibliometric data for 'Kawaii' and 'pop culture' in the 'globalisational' context

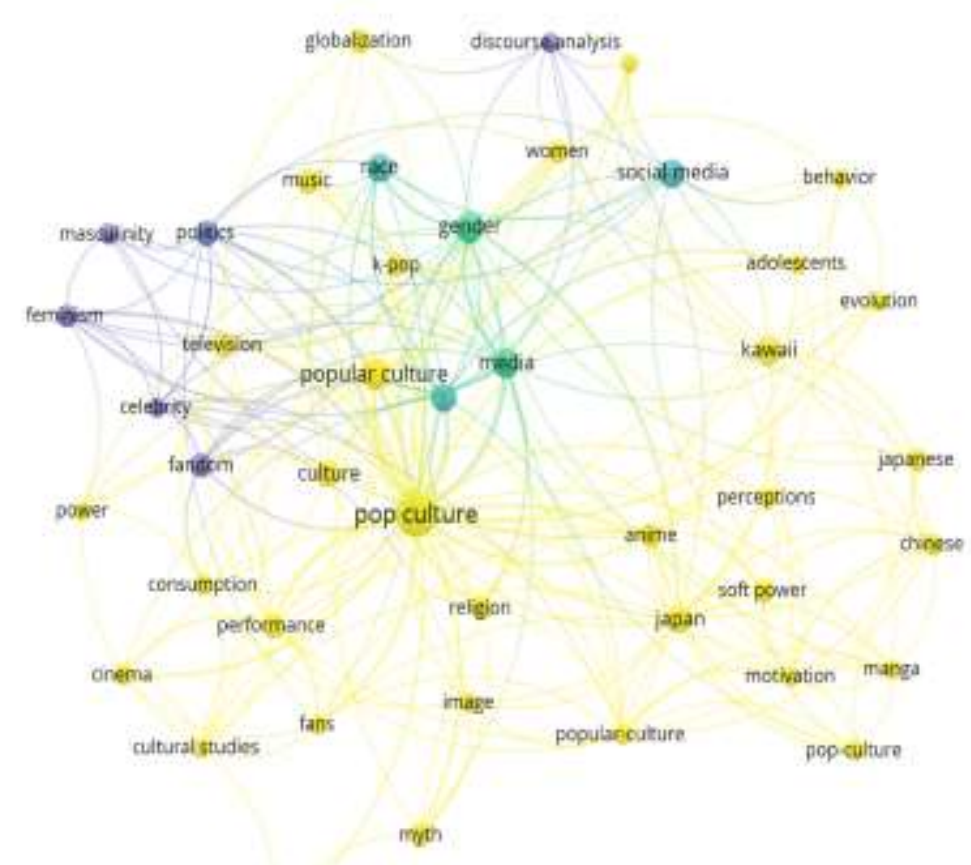

is vosviewer

$n$

Figure 2. Overlay visualisation of bibliometric data for 'Kawaii' and 'pop culture' in the 'globalisational' context 


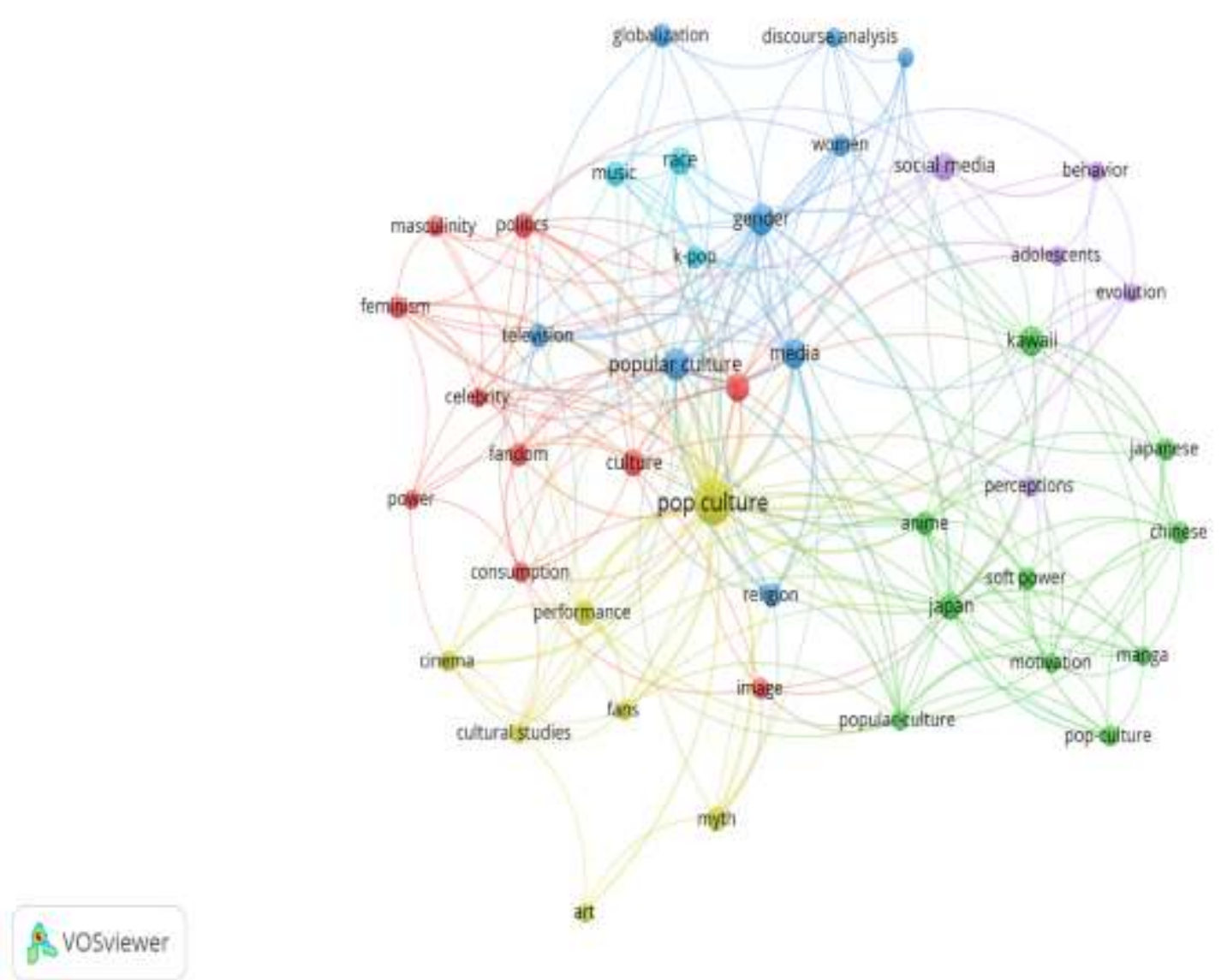

Figure 3. Co-occurrence network map of bibliometric data for 'Kawaii' and 'pop culture' in the 'globalisational' context.

4.2 Study 2: Thematic Analysis of Text Data from Three Japanese Museum Exhibitions

Following Study 1, text data was collected from special exhibitions held by three museums in Japan on the theme of 'Kawaii in Japan': 'Kawaii in Japan' at Yayoi Museum (2012), 'Osamu Harada: Finding "KAWAII"' at Setagaya Literary Museum (2019) and Fukuoka Asian Art Museum (2020). The text data of the announcements and the review of Japanese Kawaii culture were collected from the Internet Museum (2011), Bijutsu Techo (2019), Osamu Goods News (2019), and Fukuoka Asian Art Museum (2020)

Collected text data from the sources outlined above was analysed using the text mining software package, KH Coder. Descriptive analysis of the top key words (occurring more than four times) is presented in Table 3. Figure 4 illustrates an outcome of the correspondence analysis with text information from three exhibitions: Yayoi Museum (2012), Setagaya Literacy Museum (2019), and Fukuoka Asian Art Museum (2020). Notably, as the Setagaya and Fukuoka exhibitions are on the same theme of the Kawaii artist Osamu Harada, it can be observed that the two events have a different emphasis. For instance, the Setagaya event places more weight on the relevant Kawaii goods, primarily from the 1970s and 1980s, whereas the Fukuoka event seems to focus on the global context of Kawaii value transmission; this may be because Fukuoka Asia Museum has a focus on cultural interaction and impact in the Asian Pacific region in its exhibition scope.

On the other hand, the exhibition of the Yayoi museum seems to have adopted a more holistic view of Kawaiiness, with a focus that goes beyond the fancy goods or recent trends in the Japanese pop cultural movement: specifically, it focuses on a historical 
discussion originating in Japan's Taisho era (1912-1926), exhibiting nostalgic Kawaii goods and materials including letters, envelopes, and other fancy motifs that attracted young Japanese female consumers of the time. It is also interesting to note that they perceive Japanese Kawaii to have been influenced by Western cultural values and Japanese people's admiration for overseas cultures.

Table 3. Top key words extracted for the text mining analysis (frequencies of 3 and below)

\begin{tabular}{|c|c|c|}
\hline $\begin{array}{l}\text { Extracted } \\
\text { words }\end{array}$ & 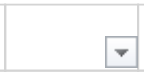 & Frequencies \\
\hline goods & Noun & 23 \\
\hline cute & Adj & 19 \\
\hline girl & Noun & 15 \\
\hline have & Verb & 14 \\
\hline culture & Noun & 13 \\
\hline fancy & Adj & 13 \\
\hline exhibition & Noun & 12 \\
\hline character & Noun & 11 \\
\hline era & Noun & 11 \\
\hline kawaii & Foreign & 11 \\
\hline book & Noun & 8 \\
\hline illustrator & Noun & 8 \\
\hline japanese & Adj & 8 \\
\hline illustration & Noun & 7 \\
\hline design & Noun & 6 \\
\hline early & Adj & 6 \\
\hline history & Noun & 6 \\
\hline bear & Verb & 5 \\
\hline become & Verb & 5 \\
\hline draw & Verb & 5 \\
\hline find & Verb & 5 \\
\hline high & Adj & 5 \\
\hline material & Noun & 5 \\
\hline product & Noun & 5 \\
\hline school & Noun & 5 \\
\hline woman & Noun & 5 \\
\hline work & Verb & 5 \\
\hline discovery & Noun & 4 \\
\hline figure & Noun & 4 \\
\hline focus & Verb & 4 \\
\hline introduce & Verb & 4 \\
\hline line & Noun & 4 \\
\hline origin & Noun & 4 \\
\hline originator & Noun & 4 \\
\hline see & Verb & 4 \\
\hline start & Verb & 4 \\
\hline thing & Noun & 4 \\
\hline time & Noun & 4 \\
\hline various & Adj & 4 \\
\hline world & Noun & 4 \\
\hline envelope & Noun & 3 \\
\hline field & Noun & 3 \\
\hline gain & Verb & 3 \\
\hline go & Verb & 3 \\
\hline hold & Verb & 3 \\
\hline last & Adj & 3 \\
\hline late & Adj & 3 \\
\hline letter & Noun & 3 \\
\hline motif & Noun & 3 \\
\hline open & Verb & 3 \\
\hline pattern & Noun & 3 \\
\hline popularity & Noun & 3 \\
\hline publish & Verb & 3 \\
\hline simple & Adj & 3 \\
\hline trace & Verb & 3 \\
\hline work & Noun & 3 \\
\hline
\end{tabular}




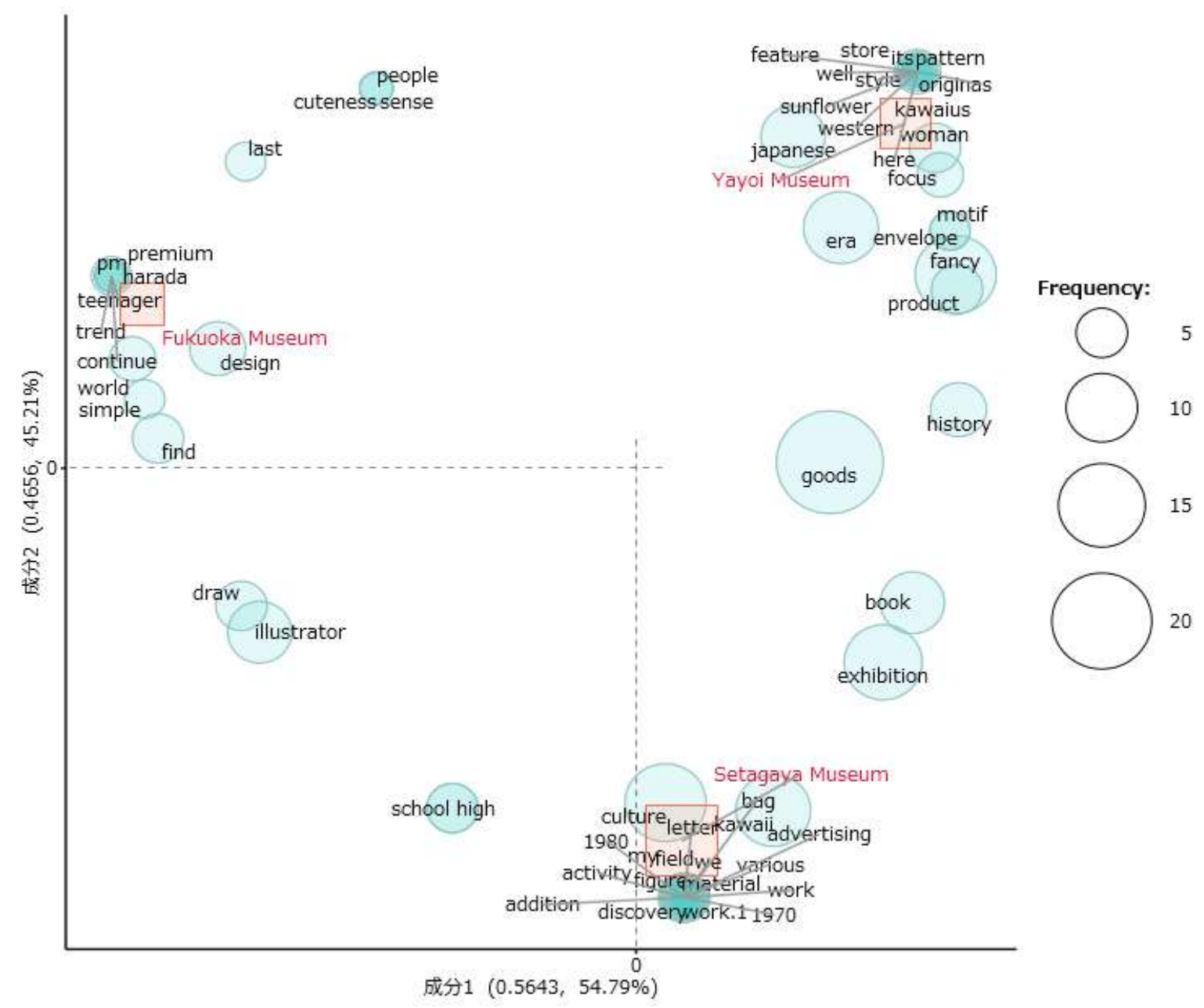

Figure 4. Correspondence map of key words contained in information about special exhibitions on the theme of 'Kawaii'

Table 4 lists the data sources for the correspondence map, developed with 41 key words found to occur more than four times. The farther away from the origin (the point at which 0 on the vertical and horizontal axes intersect), the more characteristic the word is, while strongly related words and external variables are located close together as a bubble in Figure 4. Moreover, when external variables (in this research, the three museums) are located close to each other, this indicates that the extracted categories and their occurrence times are similar. It can therefore be observed that the Yayoi museum's information is rather unique and distinctive among the three cases.

Following the overview of the text data on Japanese Kawaii extracted from the information of the museum exhibitions, a clustering map was created, which is shown in Figure 5. Out of the 398 relevant key words extracted for the analysis, a total of 41 terms were used for the cluster mapping: terms used were those with frequencies over 3 . It is further observed that six clusters were developed with the Jaccard coefficient, which determined the degree of word-to-word co-occurrence and created clusters (Higuchi, 2020b).

In Figure 5, word groups closely associated with each other are connected as merged groups to the final complete cluster. At the last phase of the merging process, two subclusters can be observed, which can be described as: (1) Key attributes of Japanese Kawaiiness and (2) Key elements of Japanese Kawaiiness (e.g. fancy goods and illustrations). 
Table 4. Data for the correspondence map of key terms

\begin{tabular}{|c|c|c|c|c|c|}
\hline & type & frequency & size & X1 & $\mathrm{X} 2$ \\
\hline goods & $\mathrm{col}$ & 23 & 79.90829 & 0.510696 & -0.00462 \\
\hline girl & $\mathrm{col}$ & 15 & 67.38945 & 0.030271 & 0.487743 \\
\hline culture & $\mathrm{col}$ & 13 & 63.76162 & -0.27138 & -0.9101 \\
\hline exhibition & $\mathrm{col}$ & 12 & 61.8428 & 0.531592 & -0.7477 \\
\hline character & $\mathrm{col}$ & 11 & 59.84221 & -0.66709 & 0.398781 \\
\hline era & $\mathrm{col}$ & 11 & 59.84221 & 1.024814 & 0.567364 \\
\hline book & $\mathrm{col}$ & 8 & 53.2196 & 0.673235 & -0.59969 \\
\hline illustrator & $\mathrm{col}$ & 8 & 53.2196 & -1.54153 & 0.384685 \\
\hline illustratior & $\mathrm{col}$ & 7 & 50.74152 & -0.83209 & 0.340607 \\
\hline design & $\mathrm{col}$ & 6 & 48.07915 & -1.28828 & 1.748868 \\
\hline history & $\mathrm{col}$ & 6 & 48.07915 & 1.098167 & -0.15566 \\
\hline material & $\mathrm{col}$ & 5 & 45.18399 & -0.60156 & -1.93176 \\
\hline product & $\mathrm{col}$ & 5 & 45.18399 & 1.438112 & 0.199557 \\
\hline school & $\mathrm{col}$ & 5 & 45.18399 & -1.10288 & -0.69632 \\
\hline woman & $\mathrm{col}$ & 5 & 45.18399 & 2.118001 & 0.909998 \\
\hline discovery & col & 4 & 41.98163 & -0.60156 & -1.93176 \\
\hline figure & $\mathrm{col}$ & 4 & 41.98163 & -0.60156 & -1.93176 \\
\hline line & $\mathrm{col}$ & 4 & 41.98163 & -1.22821 & -0.38746 \\
\hline origin & $\mathrm{col}$ & 4 & 41.98163 & 2.797891 & 1.620438 \\
\hline originator & $\mathrm{col}$ & 4 & 41.98163 & 0.248304 & -1.04371 \\
\hline thing & col & 4 & 41.98163 & 0.248304 & -1.04371 \\
\hline time & col & 4 & 41.98163 & 0.471516 & 1.388636 \\
\hline world & col & 4 & 41.98163 & -2.48151 & 2.701134 \\
\hline kawaii & col & 11 & 59.84221 & 0.016524 & -1.28591 \\
\hline we & col & 4 & 41.98163 & -0.60156 & -1.93176 \\
\hline cute & col & 19 & 73.98111 & -0.10275 & -0.02163 \\
\hline fancy & col & 13 & 63.76162 & 1.490411 & 0.254207 \\
\hline japanese & $\mathrm{col}$ & 8 & 53.2196 & 1.209773 & 1.060512 \\
\hline early & $\mathrm{col}$ & 6 & 48.07915 & 0.531592 & -0.7477 \\
\hline high & col & 5 & 45.18399 & -1.10288 & -0.69632 \\
\hline various & $\mathrm{col}$ & 4 & 41.98163 & -0.60156 & -1.93176 \\
\hline have & $\mathrm{col}$ & 14 & 65.60796 & -0.58928 & 0.594336 \\
\hline bear & $\mathrm{col}$ & 5 & 45.18399 & -0.92431 & 1.249555 \\
\hline become & $\mathrm{col}$ & 5 & 45.18399 & -0.92431 & 1.249555 \\
\hline draw & $\mathrm{col}$ & 5 & 45.18399 & -1.6042 & 0.539115 \\
\hline find & $\mathrm{col}$ & 5 & 45.18399 & -2.10552 & 1.774554 \\
\hline work & $\mathrm{col}$ & 5 & 45.18399 & -0.60156 & -1.93176 \\
\hline focus & $\mathrm{col}$ & 4 & 41.98163 & 1.948029 & 0.732388 \\
\hline introduce & $\mathrm{col}$ & 4 & 41.98163 & 0.248304 & -1.04371 \\
\hline see & $\mathrm{col}$ & 4 & 41.98163 & -0.37835 & 0.500586 \\
\hline start & $\mathrm{col}$ & 4 & 41.98163 & 0.471516 & 1.388636 \\
\hline \multicolumn{2}{|c|}{ Fukuoka Arow } & 413 & 42.09212 & -1.57868 & 1.804927 \\
\hline \multicolumn{2}{|c|}{ Setagaya I row } & 1123 & 61.24085 & -0.30554 & -0.82128 \\
\hline \multicolumn{2}{|c|}{ Yayoi Musrow } & 551 & 46.66702 & 1.421093 & 0.688922 \\
\hline
\end{tabular}




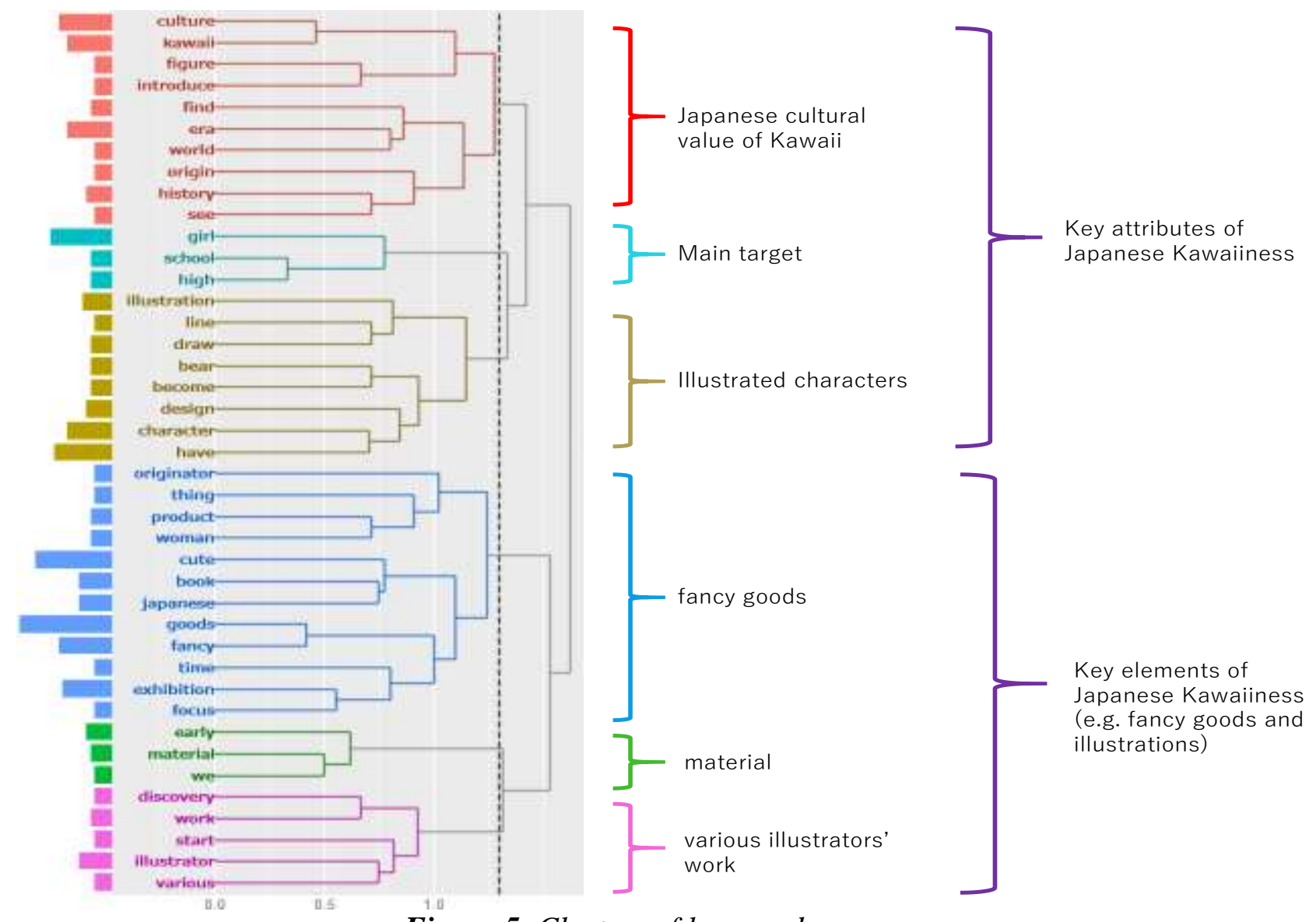

Figure 5. Clusters of key words

\subsection{Discussion}

Through the two analytical steps outlined above, cultural discussions of Japanese Kawaii have been analysed and sub-themes have been revealed to promote further discussion in the field of study. Kawaii culture, which is now one of the key themes of pop culture in Japan, has now spread all over the world, and related events are being held in various locations, as we have already seen. In the future, a unique Kawaii culture that is fused with the original cultural and social background will be nurtured in different places around the world. As it is expected that Kawaii culture will continue to attract researchers, an analytical framework containing features of dimensions with sub-themes developed from this research will provide an effective mechanism for promoting Kawaii research in the global context.

\section{Conclusion}

\subsection{Original Contribution}

This study aims to analyse Kawaii culture in Japan based on two analytical approaches: a bibliometric analysis and text mining methods. Moreover, the research outcome provides discussion themes for further study. As the present research has noted, Kawaii culture was born in Japan and has now attracted various researchers all over the world; while the current research directions and key themes can be categorised in various ways, there has been insufficient research conducting a systematic discussion that connects Kawaii culture in the Japanese and global contexts. 
The outcomes emerging from the bibliometric analysis, based on academic literature sources, and the text mining results with their correspondence map and clustering map (containing key terms from Japanese text data collected from Kawaii experts and curators), will benefit both practitioners and researchers by enabling them to enhance their understanding of Kawaii culture and foster analytical discussions in this field of study.

Currently, not only in Japan but also in other markets, relevant public sectors are acknowledging the potential of Kawaii culture as a form of pop-cultural diplomacy capable of attracting inbound tourists to sustain local businesses and communities. Accordingly, the developed framework with its sub-themes and topics could also be utilised as a useful tool for evaluating Kawaii culture with its pop fancy goods and services with attractive destinations.

\subsection{Limitations and Further Research Opportunities}

This study aims to provide a discussion framework for Kawaii cultural study from two analytical approaches: a bibliometric analysis and a text mining method. Based on the output of bibliometric analysis of Kawaii studies from the database, a framework for future research has been developed by text mining with secondary data collected from three special exhibitions launched by Japanese museums on the theme of 'Japanese Kawaii culture'.

While a developed clustering map containing key themes from Japanese Kawaii experts' and curators' perceptions of Kawaiiness will likely be a useful analytical framework for further study, the data sources for the study are limited to secondary open data. Accordingly, in future, primary data collected from both Japanese and international Kawaii fans and relevant stakeholders should be analysed in order to develop more actionable implications for this field of study. In doing so, the proposed analytical framework and agenda proposed in the research should be verified and evaluated with some more active datasets in today's global cultural market. For further research, a mixedmethods study is planned that incorporates in-depth interviews and a quantitative analysis of survey data; this will enable the development of more robust implications and recommendations for interdisciplinary researchers and practitioners.

\section{References}

Baltranaite, E., \& Povilanskas, R. (2019, January). Quantitative content analysis of the influence of natural factors on the competitiveness of South Baltic seaside resorts using the KH Coder 2.0 method. In Geophysical Research Abstracts (Vol. 21).

Beeton, S., Yamamura, T., \& Seaton, P. (2016). The Mediatisation of Culture: Japanese. Mediating the tourist experience: From brochures to virtual encounters, 139.

Beeton, S. (2019). Globalisation, tourism, and pop culture. In Handbook of Globalisation and Tourism. Edward Elgar Publishing.

Berque, D., Chiba, H., Hashizume, A., \& Kurosu, M. (2019, July). A Cross-Cultural Comparison of Perceptions of Cuteness and Kawaii Between American and Japanese College Students. In International Conference on Human-Computer Interaction (pp. 381-391). Springer, Cham.

Bijutsu Techo (2019). Koshite 'Kawaii' wa tsukurareta (This is how 'Kawaii' has ben created, Exhibition of Osamu Harada is held at Setagaya Literacy Museum, Available at https://bijutsutecho.com/magazine/news/report/20170 [Accessed 13 June 2020]

Chen, K. (2020). Unspoken Incantation: Kawaii Culture as Empowerment. Arts, University of Calgary, Available at: https://prism.ucalgary.ca/handle/1880/111590 [Accessed 27 November 2020] 
Cheok, A. D. (2010). Kawaii/cute interactive media. In Art and technology of entertainment computing and communication (pp. 223-254). Springer, London.

Cho, Y. (2017). Historicizing East Asian pop culture. The Routledge handbook of East Asian popular culture, 13-23.

Clarke, D. (2016). Theorising the role of cultural products in cultural diplomacy from a cultural studies perspective, International journal of cultural policy, 22(2), 147-163.

Ding, X., \& Yang, Z. (2020). Knowledge mapping of platform research: a visual analysis using VOSviewer and CiteSpace, Electronic Commerce Research, 1-23.

Duman, E. (2020). Kawaii Culture's Influence as Part of Japanese Popular Culture Trends in Turkey. GPJ Global Perspectives on Japan, 88-106.

Fukuoka Asian Art Museum (2020). Osamu Harada: Finding "KAWAII", Available at: https://faam.city.fukuoka.lg.jp/exhibition/10490/ [Accessed 13 June 2020]

Goldstein-Gidoni, O. (2005). The production and consumption of 'Japanese culture' in the global cultural market, Journal of consumer culture, 5(2), 155-179.

Hashizume, A., \& Kurosu, M. (2019, July). Gender difference in the free association for "Cute" and "Kawaii". In International Conference on Human-Computer Interaction (pp. 439-449). Springer, Cham.

Heng, Y. K. (2014). Beyond 'Kawaii' pop culture: Japan's normative soft power as global trouble-shoote, The Pacific Review, 27(2), 169-192.

Higuchi K. (2020a). KH Coder Index Page, Available at: https://khcoder.net/en/ [accessed 3 December 2020]

Higuchi K. (2020b). KH Coder 3 Reference Manual, Available at: https://khcoder.net/en/manual_en_v3.pdf [Accessed 3 December 2020]

Hiramoto, M., \& Wee, L. (2019). Kawaii in the semiotic landscape. Sociolinguistic Studies, 13(1), 15-35.

Internet Museum (2011). Taisho kara hajimatta Nihon no Kawaii: Exhibition started at Yayoi Museum (Japanese Kawaii originated in Taisho era in Japan: Yayoi Museum), Available at: https://www.museum.or.jp/event/78107 [Accessed 13 June 2020]

Iseri, M. (2015). Flexible femininities? Queering Kawaii in Japanese girls' culture. In Twenty-first Century Feminism (pp. 140-163). Palgrave Macmillan, London.

Iwabuchi, K. (2015). Pop-culture diplomacy in Japan: Soft power, nation branding and the question of 'international cultural exchange', International Journal of Cultural Policy, 21(4), 419-432.

Jang, K. (2020). Creating the sacred places of pop culture in the age of mobility: fan pilgrimages and authenticity through performance, Journal of Tourism and Cultural Change, 18(1), 42-57.

Kerr, H. Y. (2016). What is kawaii-and why did the world fall for the 'cult of cute'?. The Conversation, Available at:

http://irep.ntu.ac.uk/id/eprint/33176/1/PubSub10552_Kerr.pdf [Accessed 13 June 2020]

Koma, K. (2013). Kawaii as Represented in scientific research: the possibilities of Kawaii cultural studies, Hemispheres. Studies on Cultures and Societies, (28), 103-117.

Laohakangvalvit, T., Achalakul, T., \& Ohkura, M. (2019). Model of Kawaii Spoon Evaluations by Thai and Japanese. In Kawaii Engineering (pp. 173-194). Springer, Singapore.

Lieber-Milo, S. (2019). Pink Purchasing: Interrogating the Soft Power of Japan's Kawaii Consumption, Sage Open, Available at: https://pdfs.semanticscholar.org/74dd/d39564f1d47a3bda65345568ccf227c92404.pd f [Accessed 27 November] 
Lieber-Milo, S., \& Nittono, H. (2019a). From a Word to a Commercial Power: A Brief Introduction to the Kawaii Aesthetic in Contemporary Japan, Innovative Research in Japanese Studies, 3, 13-32.

Lieber-Milo, S., \& Nittono, H. (2019b). How the Japanese Term Kawaii Is Perceived Outside of Japan: A Study in Israel. SAGE Open, 9(3), 1-7.

Ministry of Foreign Affairs (2017). Pop-Culture Diplomacy, Available at: https://www.mofa.go.jp/mofaj/gaiko/culture/koryu/pop/en [Accessed 13 June 2020]

Ministry of Foreign Affairs (2012). Japan: Fascinating Diversity (Kawaii!: Inside Japanese Pop Culture), Available at: https://youtu.be/CQfWP96bIV4 [Accessed 13 June 2020]

Nittono, H. (2016). The two-layer model of 'Kawaii': A behavioural science framework for understanding Kawaii and cuteness, East Asian Journal of Popular Culture, 2(1), 79-96.

Nittono, H. (2019). Meaning of "Kawaii" from a Psychological Perspective. In Kawaii Engineering (pp. 141-144). Springer, Singapore.

Ohkura, M. (2019). Kawaii engineering. In Kawaii Engineering (pp. 3-12). Springer, Singapore.

Osamu Goods News (2019). Osamu Harada: finding Kawaii at Setagaya Literacy Museum, Available at: https://www.osamugoods.com/news/190726.html [Accessed 13 June 2020]

Pellitteri, M. (2018, September). Kawaii aesthetics from Japan to Europe: Theory of the Japanese "cute" and transcultural adoption of its styles in Italian and French comics production and commodified culture goods. In Arts (Vol. 7, No. 3, p. 24). Multidisciplinary Digital Publishing Institute.

Sabre, C. (2018). Entre kawaii et hentai, le Japon fantasmé à travers sa pop culture. Téoros. Revue de recherche en tourisme, 37(37, 2).

Sabre, C. (2019). Marketing touristique, pop culture et conflit d'appropriation: le quartier d'Akihabara à Tokyo comme vitrine du Cool Japan. Téoros: revue de recherche en tourisme, 38(2), Available at: https://www.erudit.org/en/journals/teoros/1900-v1-n1teoros04952/1065646ar/ [Accessed 27 November]

Sripian, P., Thanasuan, K., Miyatake, K., \& Ohkura, M. (2019, July). The Analysis of Kawaii Fashion in Thailand and Japan Using Colorfulness Metrics. In International Conference on Applied Human Factors and Ergonomics (pp. 224-231). Springer, Cham.

StarLifestyle (2015). Japanese kawaii culture in London, Available at: https://www.youtube.com/watch?v=Z5my3AE9euo [Accessed 13 June 2020]

Steger, B., Koch, A., \& Tso, C. (Eds.). (2020). Beyond Kawaii: Studying Japanese Femininities at Cambridge (Vol. 8). LIT Verlag Münster.

Tompkins, J. E., Lynch, T., Van Driel, I. I., \& Fritz, N. (2020). Kawaii Killers and Femme Fatales: A Textual Analysis of Female Characters Signifying Benevolent and Hostile Sexism in Video Games, Journal of Broadcasting \& Electronic Media, 1-19.

Toyoshima, N. (2008). Longing for Japan: the consumption of Japanese cultural products in Thailand. Sojourn, Journal of Social Issues in Southeast Asia, 23(2), 252-282.

Yamamura, T., \& Seaton, P. (Eds.). (2020). Contents tourism and pop culture fandom: Transnational tourist experiences. Channel View Publications.

Van Eck, N.J. and Waltman, Ludo (2020). VOSviewer Manual, Available at: https://www.vosviewer.com/documentation/Manual_VOSviewer_1.6.15.pdf [Accessed 19 December 2020]

Van Haecke, P. J. (2020). Female idols in Japan: Desiring desire, fantasmatic consumption and drive satisfaction. East Asian Journal of Popular Culture, 6(1), 77-92.

Xie, T. V. (2020). How Cross-Dressing Girls Portray the Ideal Gender in Contemporary Japan. Beyond Kawaii, Studying Japanese Femininities at Cambridge, 8, 193. 